\title{
A Cost-Effective Method to Reproduce the Morphology of the Nearshore and Intertidal Zone in Microtidal Environments
}

\author{
Stefano Furlani ${ }^{1}$ (D), Valeria Vaccher ${ }^{1, *}$, Vanja Macovaz ${ }^{2}$ and Stefano Devoto ${ }^{1}$ \\ 1 Department of Mathematics and Geosciences, University of Trieste, 34123 Trieste, Italy; \\ sfurlani@units.it (S.F.); sdevoto@units.it (S.D.) \\ 2 Department of History, Archaeology, Geography, Fine and Performing Arts, University of Florence, \\ 50121 Florence, Italy; vanja.macovaz@unifi.it \\ * Correspondence: vvaccher@units.it
}

Received: 22 April 2020; Accepted: 5 June 2020; Published: 10 June 2020

\begin{abstract}
The photogrammetric method is widely used in coastal areas and in submerged environments. Time-lapse images collected with unmanned aerial vehicles are used to reproduce the emerged areas, while images taken by divers are used to reproduce submerged ones. Conversely, 3D models of natural or human-made objects lying at the water level are severely affected by the difference in refractive index between air and seawater. For this reason, the matching of 3D models of emergent and submerged coasts has been very rarely tested and never used in Earth Sciences. The availability of a large number of time-lapse images, collected at the intertidal zone during previous snorkel surveys, encouraged us to test the merging of 3D models of emerged and submerged environments. Considering the rapid and effective nature of the aforementioned program of swim surveys, photogrammetric targets were not used during image acquisition. This forced us to test the matching of the independent models by recognizing prominent landforms along the waterline. Here we present the approach used to test the method, the instrumentation used for the field tests, and the setting of cameras fixed to a specially built aluminum support console and discuss both its advantages and its limits compared to UAVs. 3D models of sea cliffs were generated by applying structure-from-motion ( $\mathrm{SfM}$ ) photogrammetry. Horizontal time-lapse images, collected with action cameras while swimming parallel to the coastline at nearly constant velocity, were used for the tests. Subsequently, prominent coastal landforms were used to couple the independent models obtained from the emergent and submerged cliffs. The method was pilot tested in two coastal sites in the north-eastern Adriatic (part of the Mediterranean basin). The first site was a $25 \mathrm{~m}$ sea wall of sandstone set within a small harbor, while the second site was a $150 \mathrm{~m}$ route below plunging limestone cliffs. The data show that inexpensive action cameras provide a sufficient resolution to support and integrate geomorphological field surveys along rocky coastlines.
\end{abstract}

Keywords: photogrammetry; SfM; rock coasts; swim survey; Mediterranean

\section{Introduction}

Rocky coasts are the complex outcome of the work of marine and subaerial processes that result in a variety of landforms [1], in particular in the intertidal zone. This is the area of the coast that is included within the intertidal range or is underwater at high tide and above water level at low tide. Above the intertidal zone is the supratidal zone, spray zone, or splash zone, which is covered by water only during storms [2]. The shape of rocky coasts in the Mediterranean area can be classified as plunging cliffs, sloping coasts, as well as two types of shore platforms according to the shape of the platforms at the toe of the cliff, screes, and composite coasts [3,4]. Rocky coasts represent a key environment to test 
photogrammetric procedures to develop 3D models of the intertidal and nearshore zone. We focused on plunging cliffs and sloping coasts because the surface of rocky coasts covered by horizontal images is wider than on low-lying coasts [5]. Many aspects of plunging and sloping cliffs' morphologies remain unclear, mainly because of the complex logistics required to study them. Most of the studies on rocky coasts are usually carried out on selected sites, while only short sections of coast were studied using approaches of continuous swimming surveying, such as those included within the Geoswim program [6-9]. This programme was designed to collect observational and instrumental data, such as time-lapse images of long sectors of rocky coasts in sheltered basins, such as that of the Mediterranean, in particular within the intertidal and nearshore zones [5]. The great archive of time-lapse images collected at the water-level from over 10 years of expeditions encouraged us to test a method to improve the camera settings for 3D modelling during image acquisition and to test their reliability for the rocky coast studies of merged 3D models using prominent landforms to join them. The tests were carried out at two sites: a human-made wall in Italy and a vertical plunging cliff in Croatia, as shown in Figure 1. The model of the emergent part of the coast at site 2 was visually compared to the model reconstructed with a drone.

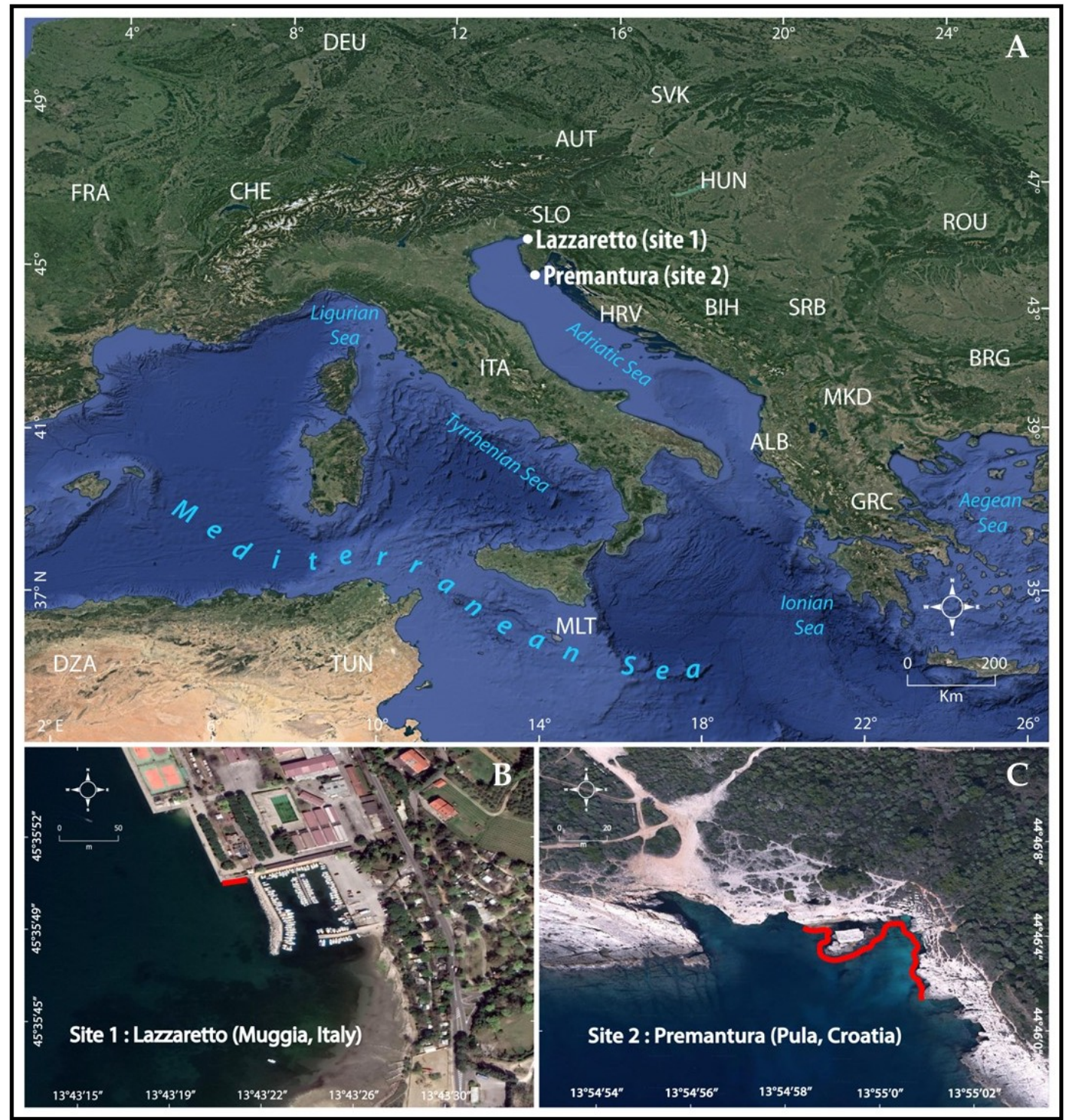

Figure 1. (A) The studied sites are highlighted with white circles; (B) site 1, Lazzaretto harbor (Trieste, Italy); (C) site 2, Premantura (Pula, Croatia). 
The models were built using the SfM low-cost photogrammetric method [10], which are widely used in coastal, submarine and inland settings, but are rarely used at the waterline. The main problems arise from the different optical settings of the cameras above the water level (awl) and below the water level (bwl), caused by differences in the refractive index between air and water, or the related "lens effect". Menna et al. [11] published an exhaustive paper discussing the procedures for the alignment of independent emergent and submerged models. However, there is undoubtedly a lack of photogrammetric reconstructions of the intertidal and nearshore zones for Earth Science studies.

SfM, applied to geosciences, has been subject to increasing interest as a result of the enhancement of hardware and software performance [12]. Not surprisingly, rocky coast studies have also witnessed this ever-increasing interest in SfM technologies for gathering fundamental data in difficult-to-access environments [13], such as semi-submerged sea caves [14]. In the last decade, automated aerial and close-range digital photogrammetry has become a powerful and widely used tool for three-dimensional topographic modelling [15-17]. Abadie et al. [18] used georeferenced photogrammetry to map marine habitats on submerged artefacts. Drap et al. [19] suggested that photogrammetry in underwater contexts makes it possible to obtain a comprehensive survey of all visible parts of the site without impacting the studied objects, either natural or human-made. SfM photogrammetry offers the possibility of the fast, automated, and low-cost acquisition of 3D data [20]. The high level of automation involved in SfM data processing creates both opportunities and threats, particularly because user control tends to focus upon the visualization of the final product rather than upon the inherent data quality [20]. Underwater 3D reconstruction techniques, such as underwater photogrammetry, represent the latest trend in low-cost survey techniques [21]. The authors in [21] suggested that these methods permit the creation of high-resolution models using digital cameras and editing software, and in shallow water environments, these provide a viable alternative to costly methods, such as light detection and ranging (LiDAR) and Sonar. Moreover, photogrammetric methods have been used in geomorphology using data acquired by UAVs [22] or submerged images collected by scuba divers, sometimes coupled with acoustic data [23]. The joint alignment of underwater and above-water 3D models was successfully tested by [11] on human-made structures, mainly involving engineering issues.

\section{Description of the Study Area}

Both sites are located on the north-eastern Adriatic coast (Italy and Croatia, northern Mediterranean), as shown in Figure 1A. Site 1, shown in Figure 1B, is a small harbor within a sheltered bay in Italy, south of Trieste and at the border of Slovenia. The survey was performed on the sandstone seawall of a military base. The area is dominated by carbonate and marly-sandstone rocks belonging to the Adriatic Carbonate Platform [24]. Site 2, shown in Figure 1C, is located at the southernmost tip of the Istrian Peninsula, where plunging limestone cliffs occur. Recently, [25] modelled the emergent and submerged platform hosting storm-wave boulders near the studied site. The authors reported very strong south-easterly winds and waves.

The area is characterized by the prevalence of winds blowing from the first quadrant, mainly from the ENE (Bora) [26]. South-easterly winds are important because of their longer geographical fetch (over $800 \mathrm{~km}$ ). Tides are semi-diurnal, with mean spring-tide values of $0.86 \mathrm{~m}$ in Trieste, and mean neap-tide values of $0.22 \mathrm{~m}[27,28]$. The concomitance of spring tides, seiches, south-easterly winds, and low atmospheric pressure can cause a sea-level rise of $1.80 \mathrm{~m}$. The mean significant wave height during the year is lower than $0.5 \mathrm{~m}$ [29], while the highest offshore wave height, both for Bora and Scirocco storms, is about $5 \mathrm{~m}$ [30]. The mean annual near-surface temperature in Trieste is about $16{ }^{\circ} \mathrm{C}$ [31]. 


\section{Materials and Methods}

The methodology implemented and described in this paper is inexpensive and relatively quick. Details of the image acquisition system, and data processing are given in Section 3.1 to Section 3.3. In Section 3.4, we also provide a description of the drone used in the project.

The approach of the acquisition and processing of time-lapse images is summarized in Figure 2.

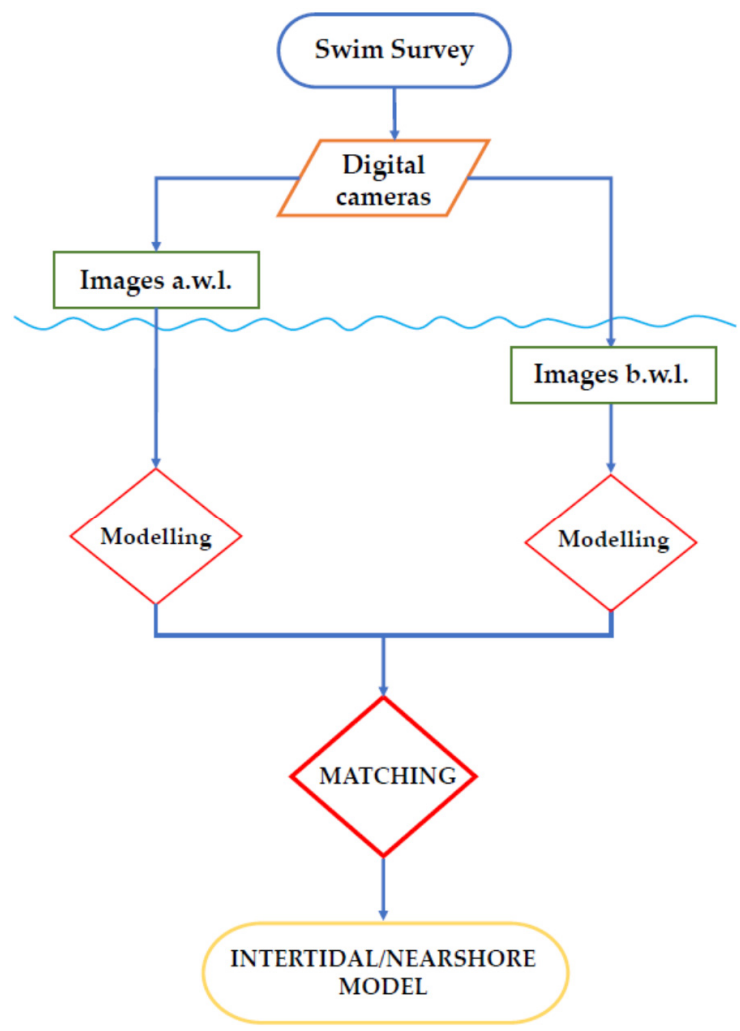

Figure 2. Diagram of the acquisition and modeling procedures.

\subsection{Support Console and Cameras}

The support console consisted of a set of $20 \times 20 \mathrm{~mm}$ aluminum bars, shown in Figure 2, fixed together for their purpose, on which three cameras were attached. The support was hosted on a raft $1.2 \mathrm{~m}$ long, used within the Geoswim program, which is well-described by [5]. One GoPro Hero Black 5 was fixed on the support at $+0.35 \mathrm{~m}$ awl, and up to two GoPRO Hero Black 6s were fixed at $-0.35 \mathrm{~m}$ bwl within plastic domes produced by Telesin, shown in Figure 3, in order to preserve the field of view (FOV) and focal length of the camera-lens system [32].

We used one camera bwl at site 1 , because the sea wall is vertical and homogeneous. Conversely, since the plunging cliffs at site 2 are more jagged, we used two cameras bwl, in order to increase the number of available images. This allowed us to avoid an unpleasant lack of images in the event of technical malfunctions, and to get more images of the same targets of the cliff, in order to reduce shading effects and to choose the best images. The positions of the cameras with respect to the waterline were chosen in order to better cover the intertidal zone and surroundings. The mutual orientation of the cameras bwl and their depth with respect to the waterline were chosen in order to be sure of covering the widest target surface, as shown in Figure 4. The cameras were set in fish-eye mode, or ultra-wide angle, both awl and bwl. The camera inclination can be adjusted, but it was set in a horizontal position and perpendicularly to the swimming direction. The cameras bwl were positioned in the same way, but each was $5^{\circ}$ convergent, as shown in Figures 3 and 4 . 


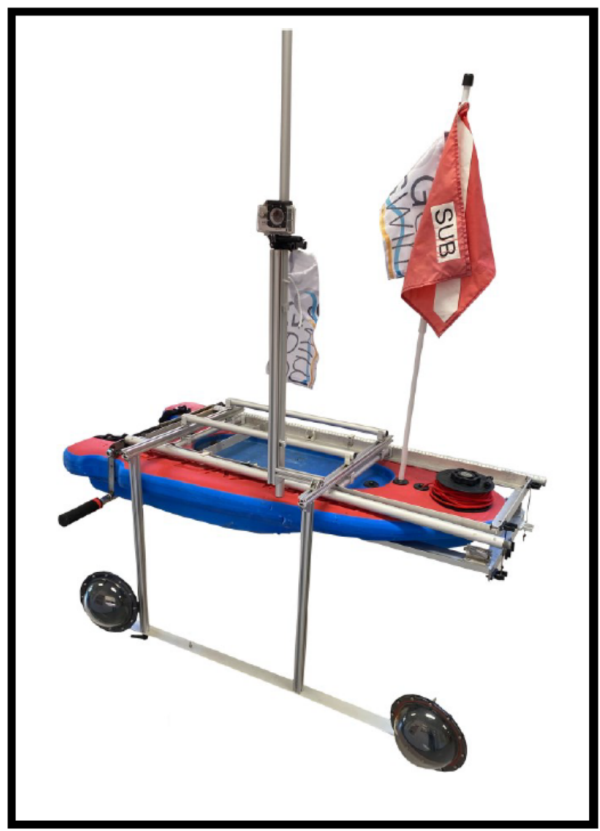

Figure 3. Lateral view of the raft with the support console.

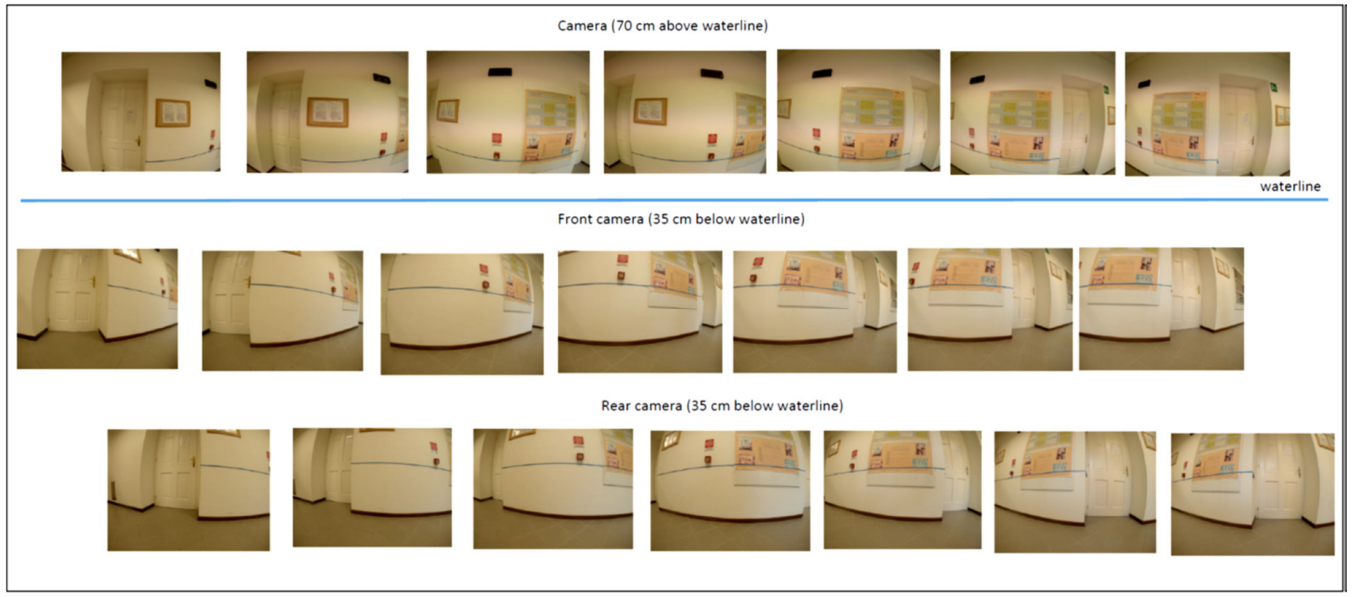

Figure 4. Time-lapse images collected in the laboratory corridor. The first line corresponds to the camera above the waterline, while the second and third lines collected images at lower elevations that correspond to the submerged setting. As aforementioned, the latter cameras are slightly convergent.

\subsection{Acquisition Setting and Data Collection}

Time-lapse images, shown in Figure 4, were collected at two sites along the north-east Adriatic coast: Site 1-Lazzaretto harbor (Muggia, Trieste, Italy); Site 2-Premantura (Pula, Croatia), as shown in Figure 1. Moreover, a laboratory test at the University of Trieste was carried out in order to calibrate the settings of the cameras.

Below, we describe the procedures developed for collecting time-lapse images in the field and the strategies designed to optimize image quality and overlay.

The GoPROs were set in time-lapse mode, with one shoot every $0.5 \mathrm{~s}$ or $1 \mathrm{~s} \mathrm{bwl}$, and $1 \mathrm{~s}$ awl, as shown in Figure 4. The time-lapse images were collected while swimming parallel to the coast, at an average distance of $1 \pm 0.5 \mathrm{~m}$ away from shore, at a speed around $1 \mathrm{~km} / \mathrm{h}$. In correspondence to topographical obstructions (such as submerged or semi-submerged rocks, boulders, etc.), the route was changed slightly from that planned, but still guaranteed photo coverage by reducing the speed, for example. However, thanks to the characteristics of the software used for reconstructing the 3D models, small differences in swimming speed do not affect the resolution of the models. GoPROs are 
so-called "actioncams", mainly devoted to creating videos of extreme sport activities. The GoPRO Hero 5 and 6 are fixed-focus still-frame cameras, (or 1080p high-definition video cameras), whose small form-factor and waterproof housing have made them popular with sports enthusiasts (GoPRO technical manuals). Both cameras have a resolution of 12 megapixels $(4000 \times 3000)$ in discrete image capture. They have a continuous shooting mode (time-lapse mode) with a nominal maximum rate of two images per second. The nominal focal length of the GoPro camera is $3 \mathrm{~mm}$ and the pixel size is $1.73 \mu \mathrm{m}$. Assuming no radial distortion, the area covered by a horizontal image taken $1 \mathrm{~m}$ from the coastline is $3.0 \mathrm{~m} \times 4.0 \mathrm{~m}$, which corresponds to a ground sampling distance (GSD) of $1.7 \mathrm{~mm}$ [25]. The GoPROs were set to collect time-lapse images every second, or 3600 images/hour. Swimming at $1 \mathrm{~km} / \mathrm{h}$ (about $0.3 \mathrm{~m} / \mathrm{s}$ ), the camera shoots every $0.3 \mathrm{~m}$, as shown in Figure 5.

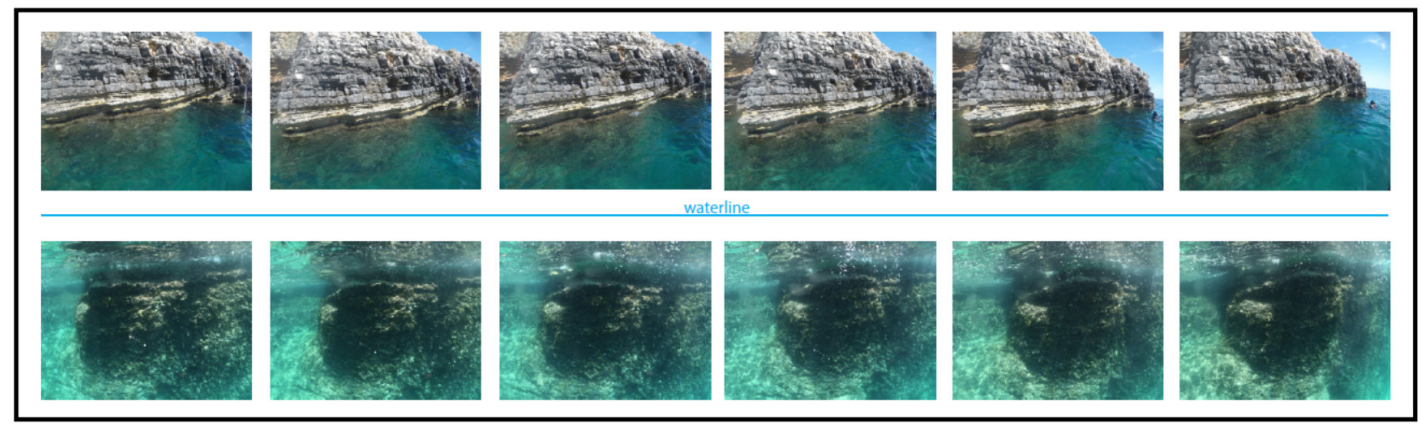

Figure 5. A set of time-lapse images collected awl and bwl at site 2 (Premantura, Croatia). Overlap exceeds $90 \%$ at the aforementioned selected swimming speeds. The system is mainly intended for corridor mapping along the waterline with a single strip. If needed, a camera inside the dome in the bow, shown in Figure $6 A, C, D$, at the water level can be used to film the survey operations.

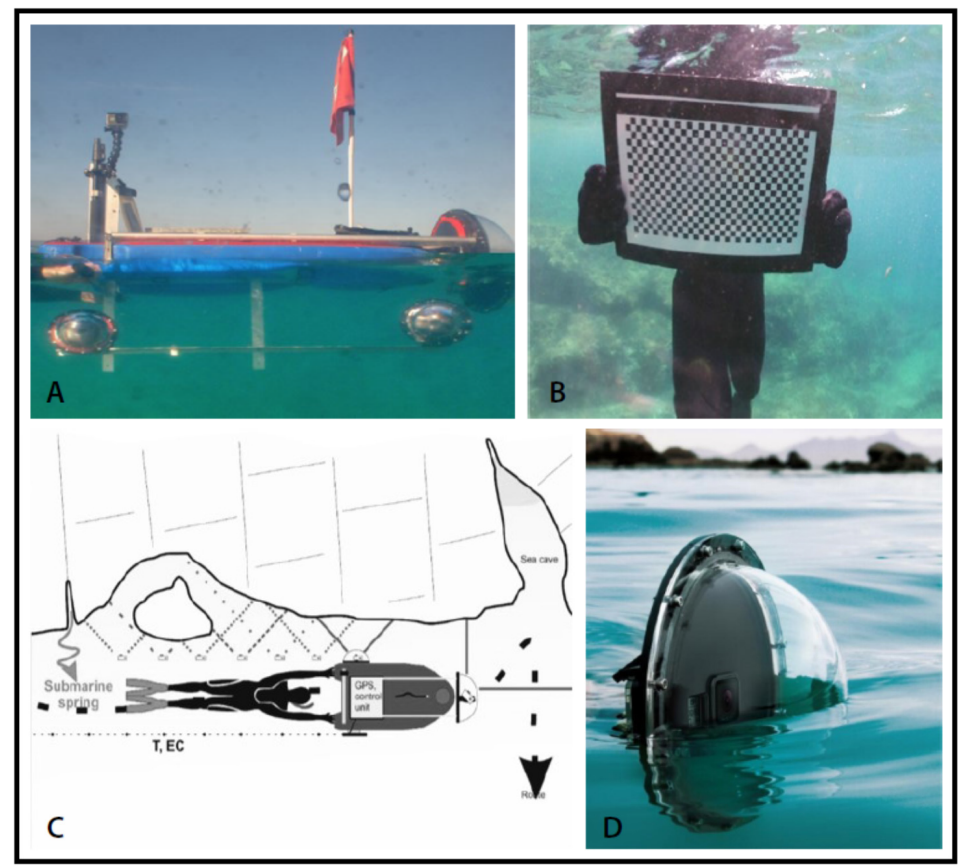

Figure 6. (A) The configuration of the cameras hosted on the raft used for the photogrammetric acquisition; (B) Underwater/subaerial photogrammetric target used to calibrate the distortion index due to surface roughness in underwater photogrammetry; (C) Sketch of the acquisition of time-lapse images along the coastal routes. The swimming is carried out at $1 \pm 0.5 \mathrm{~m}$ from the shore, at a speed of about 1 to $2 \mathrm{~km} / \mathrm{h}$. The camera positioned within the dome at the front of the raft, inclined at $45^{\circ}$ with respect to the coastline, is used to document the survey; (D) The cameras within the domes mounted laterally are positioned at $-0.5 \mathrm{~m}$ below the waterline and at $1 \mathrm{~m}$ above. 
The distortion index in underwater photography was calibrated using a print target made using a regular W/B patch grid, shown in Figure 6B.

The grid, or patch size, represents the relative size of each box compared to the neighbor. Images of the target were collected in every part of the printed patch, summarizing the entire surface of interest, in order to obtain a perfect correction model. Images were georeferenced and assigned on the map using the integrated GPS tags of the camera awl. The GoPRO GPS precision is not provided by the company, but usually it is $1 \mathrm{~m}$ under open sky, and worsens close to obstacles, such as sea caves, etc. GPS data were used only to accelerate the process of tie point generation, since the software compares only nearby images [Technical Manual of Metashape, 2019].

\subsection{Post-Processing of Time-Lapse Images}

Time-lapse images were included in the photogrammetric process to obtain 3D models. They have become a key concept in geosciences for modelling topographic surfaces, and for the monitoring of spatial and temporal changes in natural environments [33]. A wide range of commercial and open source software tools enable the generation of 3D models of complex geomorphological features, including by geoscientists and other non-experts [34]. In particular, SfM is a photogrammetric range imaging technique for estimating three-dimensional structures from two-dimensional image sequences. SfM offers Earth scientists a tool for building high-resolution models at a range of scales and for detection purposes. SfM allows the use of consumer-grade digital cameras and highly automated data processing, and it is based upon algorithms for the efficient and automatic orientation of large image datasets without further acquisition information [34].

3D structures can be resolved from a series of overlapping, offset images. The automatic camera coordinates estimation algorithms simultaneously allow the operators to identify 3D camera location and scene geometry [20]. Automatic internal and external orientation are important innovations in the SfM method. Digital photogrammetry works using recursive analysis to determine the external orientation from the inner one, using the images' metadata. Normally, photographs are distorted in some way with respect to a perfect monoscopic projection. The distortion of the images allows analysts to determine where and which points are not in the right position on the photo (internal orientation of the camera). These parameters change with the focal length and, therefore, a pixel situated in two different positions in two different images can be represented with a different projection. Metadata are processed by software, so it is also possible to obtain a correction profile starting from them and computing the average error from every single image of a dataset.

Color corrections were performed using Photoshop CC 2019, while images were processed using Agisoft Metashape 1.5.0 workflow [35], in order to create the mesh models.

Tie points (TPs) were created using Agisoft Metashape. They represent the number of recognized features and define the total population of common points for each image. The software also creates the connections between them. Then, the dense cloud process defines the model at a more detailed level, creating up to 93 times more points than the tie point cloud. The final 3D model is a set of multiple triangles linking the points. The model can be displayed using a color film, called texture, over each mesh triangle.

The emergent and underwater models were obtained independently from images collected awl and bwl, thus each model has its own arbitrary datum. In order to join up the emergent and submerged part of the coastline, at the end of the procedure the independent models were oriented and jointed using a common coordinates system.

Menna et al. [11] suggested joining up the separated models using calibrated Orientation Devices (ODs), such as rigid bars. We did not use this technique as much as the image dataset was collected during very rapid expeditions. For this reason, the models were linked up using prominent features of the coastline instead of ODs, as at site 2, shown in Figure 4. A 2 m-long aluminum bar was used as a vertical reference to define the model orientation, to determine the $\mathrm{z}$ axis, and to scale the models. 


\subsection{UAV Comparison}

To validate the models, we performed a UAV survey using a DJI Spark drone (DJI, Nanshan District, Shenzhen, China). This UAV is categorized as a micro drone, according to the weight classification proposed by [36]. Micro drones are widely used in various fields of geoscience and offer major benefits for their maneuverability during flight operations and landing phases. In addition, these drones can provide high-resolution images from reduced flight times $[37,38]$. Unmanned aerial vehicles - digital photography (UAV-DP) — enabled the reconstruction of high-resolution point clouds, orthophotographs and 3D models of the sea cliffs studied. These models were compared with that produced using horizontal images collected awl from the raft.

Shots were taken every $2 \mathrm{~s}$ and the drone was piloted manually $25 \mathrm{~m}$ above sea level and approximately $15 \mathrm{~m}$ from the plunging cliffs with the camera orientation set at approximately $45^{\circ}$ towards the terrain in order to avoid a lack of coverage on the vertical structure [10].

The model was produced through the processing of 247 images acquired by the drone in February 2020, with the same procedure followed with horizontal time-lapse images.

\subsection{Weather Data during the Surveying Days}

Weather data for the surveying days were obtained, respectively from the meteorological station at Muggia (ARPA FVG), $5 \mathrm{~km}$ from site 1, and from the station of the Croatian Meteorological and Hydrological Service of Pula, $13 \mathrm{~km}$ from site 2. The data are reported in Table 1.

Table 1. Weather conditions during the survey days. The table includes precipitation (mm), temperature $\left({ }^{\circ} \mathrm{C}\right)$, relative humidity $(\%)$, wind speed $(\mathrm{Km} / \mathrm{h})$, direction, and sea temperature $\left({ }^{\circ} \mathrm{C}\right)[31]$.

\begin{tabular}{|c|c|c|c|c|c|c|c|c|}
\hline $\begin{array}{l}\text { Survey } \\
\text { Sites }\end{array}$ & Date & $\begin{array}{l}\text { Time } \\
\text { [UTC] }\end{array}$ & $\begin{array}{l}\text { Rain } \\
{[\mathrm{mm}]}\end{array}$ & $\begin{array}{l}\text { Temp } \\
{\left[{ }^{\circ} \mathrm{C}\right]}\end{array}$ & $\begin{array}{c}\text { Relative } \\
\text { Humidity [\%] }\end{array}$ & $\begin{array}{l}\text { Wind Speed } \\
{[\mathrm{km} / \mathrm{h}]}\end{array}$ & $\begin{array}{c}\text { Wind } \\
\text { Direction }\end{array}$ & $\begin{array}{c}\text { Sea Temperature } \\
{\left[{ }^{\circ} \mathrm{C}\right]}\end{array}$ \\
\hline \multirow[b]{2}{*}{ Lazzaretto } & $16 / 08 / 2019$ & 07:00 & 0.0 & 22.9 & 53 & 27 & ESE & 27.5 \\
\hline & $16 / 08 / 2019$ & $14: 00$ & 0.0 & 27.2 & 40 & 15 & $\mathrm{E}$ & 27.2 \\
\hline \multirow[t]{2}{*}{ Premantura } & $21 / 06 / 2019$ & 07:00 & 0.0 & 25.7 & 71 & 11 & E & 25.8 \\
\hline & $21 / 06 / 2019$ & $14: 00$ & 0.0 & 31.0 & 50 & 10 & SE & 26.2 \\
\hline \multirow{2}{*}{$\begin{array}{c}\text { Premantura } \\
\text { (UAV } \\
\text { survey) }\end{array}$} & $21 / 06 / 2019$ & $21: 00$ & 0.0 & 25.4 & 70 & 6 & ESE & 26.2 \\
\hline & $20 / 02 / 2020$ & $21: 00$ & 0.0 & 5.3 & 57 & 10 & NE & 10.9 \\
\hline
\end{tabular}

No rainfall events were observed, while the sea and air temperatures conformed to seasonal data and ranged between $25.8^{\circ} \mathrm{C}$ and $27.5^{\circ} \mathrm{C}$. The highest wind speed blew from the second quadrant, shown in Table 1. The tide elevations during the surveys were measured and corrected using the tide gauge in Trieste. No correction was applied for site 1, because it is located close to the gauge. A $25 \mathrm{~min}$ advance was applied for site 2, considering the $70 \%$ tide amplitude in Trieste [39,40]. At site 1, the tide was $-5 \mathrm{~cm}$ below mean sea level, and at site 2 during the June survey, the tide was $0 \mathrm{~cm}$ above mean sea level, while at site 2 during the UAV survey, the tide was $+5 \mathrm{~cm}$ above mean sea level.

\section{Case Studies}

Data from site 1 are described in Section 4.1, site 2 in Section 4.2, and drone acquisition in site 2 is described in Section 4.3.

\subsection{Site 1}

The acquisition of time-lapse images was carried out on the 16 August 2019 along a test route of $25 \mathrm{~m}$, shown in Table 1, at site 1, on the southernmost sector of a seawall, shown in Figure 1B. The acquisition area is located in a very sheltered bay. The seawall is composed of regular sandstone blocks ranging in length from $0.10 \mathrm{~m}$ to $0.5 \mathrm{~m}$. 
The sea and weather conditions were perfect at the time the survey was undertaken, shown in Table 2, with a very calm sea, this being a sheltered site. The raft was very stable during the surveying activities, without significant rolling and pitching. Moreover, the good sea conditions allowed the raft to be pushed parallel to the coastline.

Table 2. Acquisition parameters of the seawall at Lazzaretto (Italy).

\begin{tabular}{ccccccccc}
\hline & Number of Images & Frequency [n/s] & Starting Point & Ending Point & Camera & Elevation [m] & Dome [Y/N] & Markers [Y/N] \\
\hline awl & 298 & 1 & $45^{\circ} 35^{\prime} 50.33^{\prime \prime} \mathrm{N}$ & $45^{\circ} 35^{\prime} 50.09^{\prime \prime} \mathrm{N}$ & GoPro 5 & 1 & $\mathrm{~N}$ & $\mathrm{Y}$ \\
bwl & 213 & 1 & $13^{\circ} 43^{\prime} 18.33^{\prime \prime} \mathrm{E}$ & $13^{\circ} 43^{\prime} 17.29^{\prime \prime} \mathrm{E}$ & GoPro 6 & 0.5 & $\mathrm{Y}$ & $\mathrm{N}$ \\
\hline
\end{tabular}

A total of 511 images were collected, 298 above the waterline and 213 below it at a rate of one per second, shown in Table 2. Table 2 reports all the acquisition parameters set for this test. The emerged and underwater acquisitions were conducted using the same parameters and following the same route, but a GoPro Hero 5 was used awl and a GoPro Hero 6 was used bwl, shown in Figure 7.

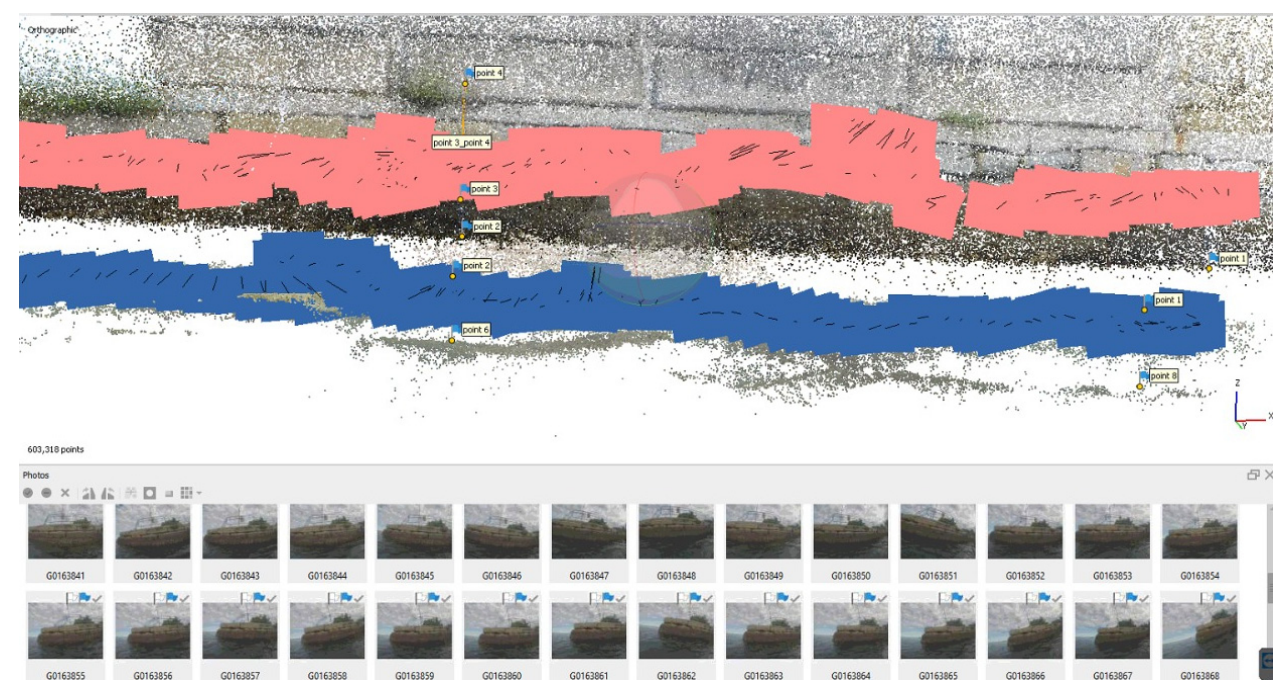

Figure 7. The acquisition points at site 1.

\subsection{Site 2}

The acquisition of time-lapse images was carried out on the 21 June 2019 on a route of $150 \mathrm{~m}$, shown in Figure 4, along plunging cliffs in the southeasternmost sector of the Premantura peninsula (Croatia), east of the entrance to a small sea cave, shown in Figure 1C. The acquisition area is exposed to southerly winds. The plunging cliffs are composed of horizontal decametric limestone beds.

The sea conditions were calm during the surveying activities, being a sheltered site, shown in Figure 1, with a weak SE wind, shown in Table 1, so the raft was stable, without significant rolling and pitching during the surveying activities. The good sea conditions allowed the raft to be pushed parallel to the coastline. However, some submerged blocks and outcrops prevented the perfect following of a route parallel to the coastline in the western sector.

Field acquisition was carried out using three cameras: one GoPro Hero 5 was set awl while two convergent GoPro Hero 6s were set bwl. In total, 715 images were collected above the waterline and 1453 from each camera below it, shown in Table 3. Images were georeferenced and localized on the map, using the integrated GPS tags of the camera awl, shown in Figure 8.

Table 3. Acquisition parameters of the plunging cliffs at Premantura (Croatia).

\begin{tabular}{ccccccccc}
\hline & Number of Images & Frequency [n/s] & Starting Point & Ending Point & Camera & Elevation [m] & Dome [Y/N] & Markers [Y/N] \\
\hline awl & 715 & 1 & $44^{\circ} 46^{\prime} 4.34^{\prime \prime} \mathrm{N}$ & $44^{\circ} 46^{\prime} 5.14^{\prime \prime} \mathrm{N}$ & GoPro 5 & 1 & $\mathrm{~N}$ & $\mathrm{Y}$ \\
bw1 & 1453 & 0.5 & $13^{\circ} 55^{\prime} 0.48^{\prime \prime} \mathrm{E}$ & $13^{\circ} 54^{\prime} 57.90^{\prime \prime} \mathrm{E}$ & GoPro 6 & 0.5 & $\mathrm{~N}$ & $\mathrm{~N}$ \\
\hline
\end{tabular}




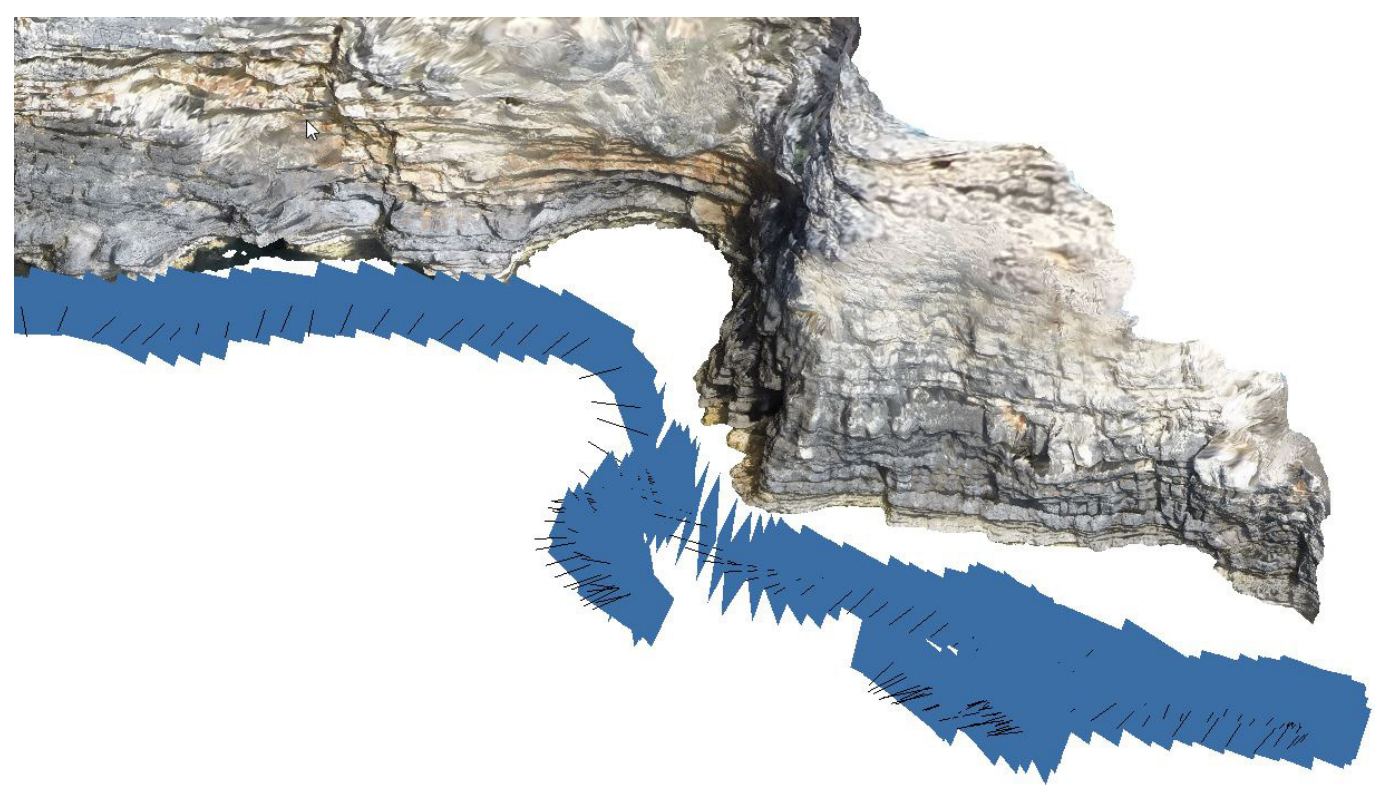

Figure 8. Set of acquisition points with the camera awl at site 2. Blue squares represent the relative position of the camera during the shooting and are perpendicular to the direction of acquisition, the latter represented with the black lines.

\subsection{UAV Imagery at Site 2}

The acquisition of time-lapse images with UAV was carried out on 20 February 2020 at site 2, shown in Figure 1C, using the parameters of acquisition described in Table 4. The acquisition points with the drone at site 2 are shown in Figure 9, together with the dense cloud model.

Table 4. Acquisition parameters with UAV at Premantura (Croatia).

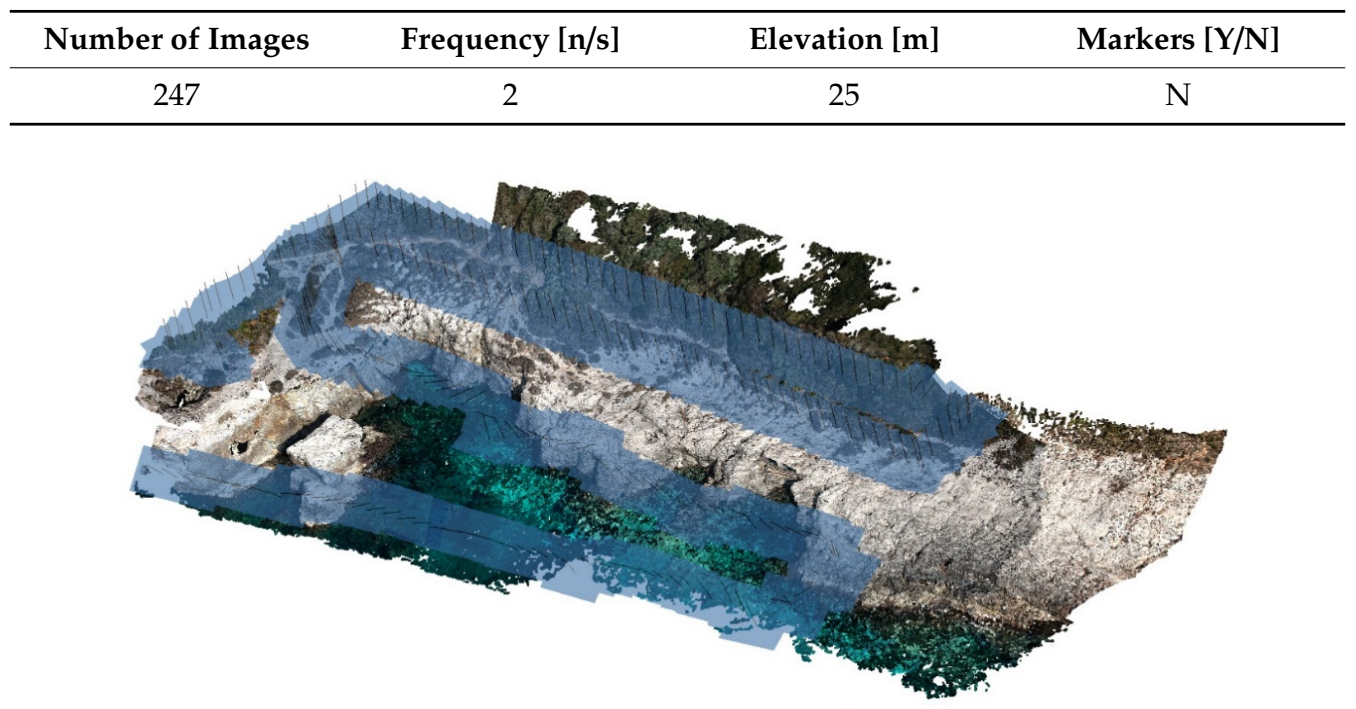

Figure 9. Dense cloud and acquisition points with drone at site 2.

The weather was sunny and the sea very calm, as shown in Table 1.

\section{Data Post-Processing and Production of 3D Models}

Time-lapse images and UAV images were used to produce 3D models of the intertidal and nearshore zones. The following sections show the models obtained and describe the analysis parameters of each case study at sites 1 and 2 . 


\subsection{D Model at Site 1}

A total of 413,025 TPs were obtained from 298 images, using high-quality analysis, shown in Table 5 . The alignment of the emergent and submerged parts of the seawall was done using the groups of markers previously described.

Table 5. Elaboration parameters of the seawall at Lazzaretto.

\begin{tabular}{cccc}
\hline & & awl & bwl \\
\hline Number of images & & 298 & 213 \\
\hline Markers (Y/N) & & 7 & 7 \\
\hline \multirow{2}{*}{ TPs } & $\mathrm{n}^{\circ}$ & 413,025 & 190,293 \\
\cline { 2 - 4 } & Quality & High & High \\
\hline \multirow{2}{*}{ Dense cloud } & $\mathrm{n}^{\circ}$ & $3,847,764$ & $8,336,219$ \\
\cline { 2 - 4 } & Quality & Medium & High \\
\hline
\end{tabular}

Figure 10C,D show that the sandstone blocks are easily distinguishable awl. The dark brown color refers to the high intertidal band, while above it is the splash zone. Intertidal organisms can also be distinguished, in particular limpets, such as Patella Cerulea, and oysters. The resolution of the bwl model, shown in Figure 10E,F, also permits us to distinguish the organisms. In Figure 10F, at the bottom right, brown algae are visible. The sandstone blocks are less distinguishable bwl because they are partially covered by organisms. The awl/bwl transition is influenced by the intersection of the respective models and by wave movements.

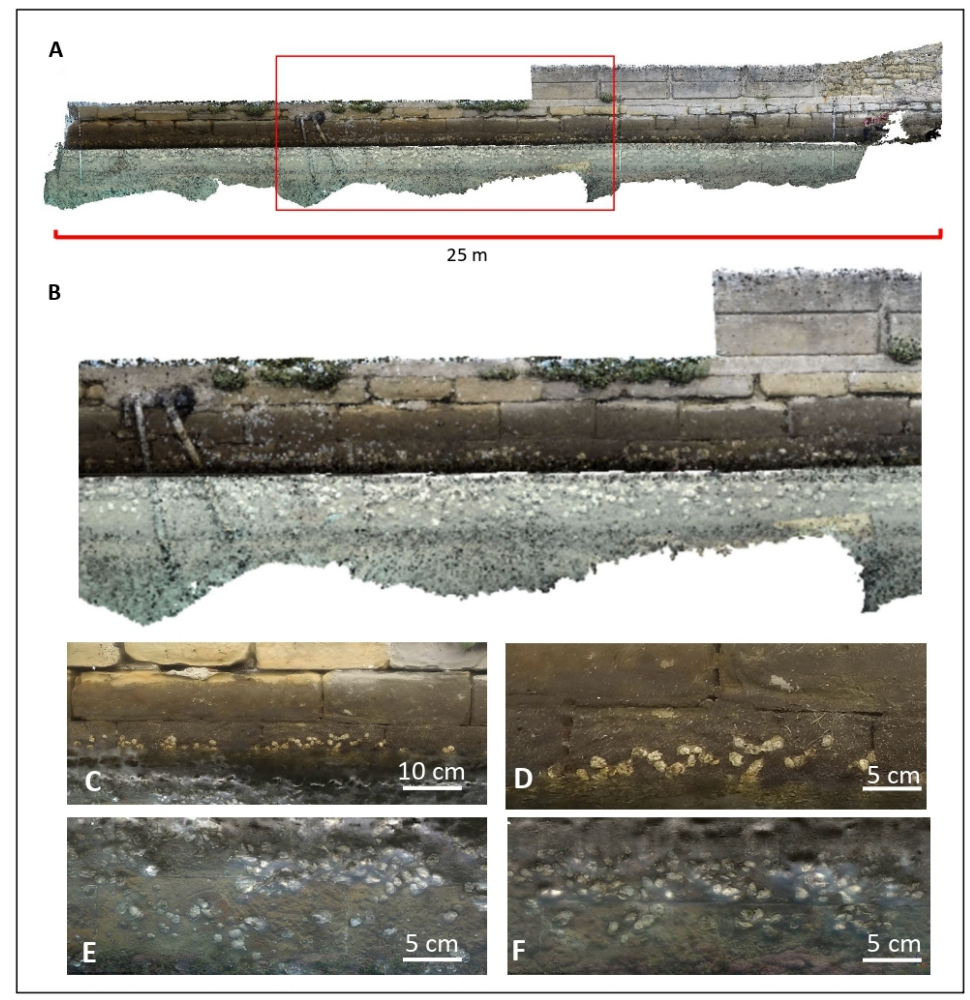

Figure 10. (A) Dense cloud of the jointed model of the seawall; (B) textured model of an enlargement (red square in $\mathbf{A}$ ) of the seawall at site 1. This model shows the puzzle joining of the emergent and submerged models, awl and bwl (C and D) enlargements of the model awl; (E and F) enlargements of the model bwl. 


\subsection{D Model at Site 2 with Horizontal and Drone Images}

At Kamenjak, Premantura, the survey was carried out with good sea and weather conditions, as testified by the weather data, shown in Table 1, and therefore the boundary conditions of the test were excellent.

Table 6 summarizes the total number of TPs and points in the Dense Cloud. Due to the large number of images, the reference preselection function was used during the alignment process. This forced the software to match only nearby images, therefore reducing the time required for alignment.

Table 6. Elaboration parameters of the plunging cliffs at Premantura.

\begin{tabular}{cccc}
\hline & & awl & bwl \\
\hline Number of images & & 715 & 1453 \\
\hline Markers (Y/N) & & 2 & $/$ \\
\hline \multirow{2}{*}{ TPs } & $\mathrm{n}^{\circ}$ & $1,577,941$ & 400,478 \\
\cline { 2 - 4 } & Quality & High & High \\
\hline \multirow{2}{*}{ Dense cloud } & $\mathrm{n}^{\circ}$ & $18,383,030$ & $37,567,000$ \\
\cline { 2 - 4 } & Quality & Medium & Medium \\
\hline
\end{tabular}

The distortion decreased using the top and bottom of the iron bar used to define the $\mathrm{z}$ axis. The awl model was positioned using the GPS tags of the GoPRO images, while the bwl model was scaled and aligned to the awl model using prominent landforms along the coastline.

Part of the jointed model, obtained from the alignment of independent emergent and submerged models, is shown in Figure 11. The matching process was difficult, mainly because images that lay at sea level did not perfectly coincide with each other.

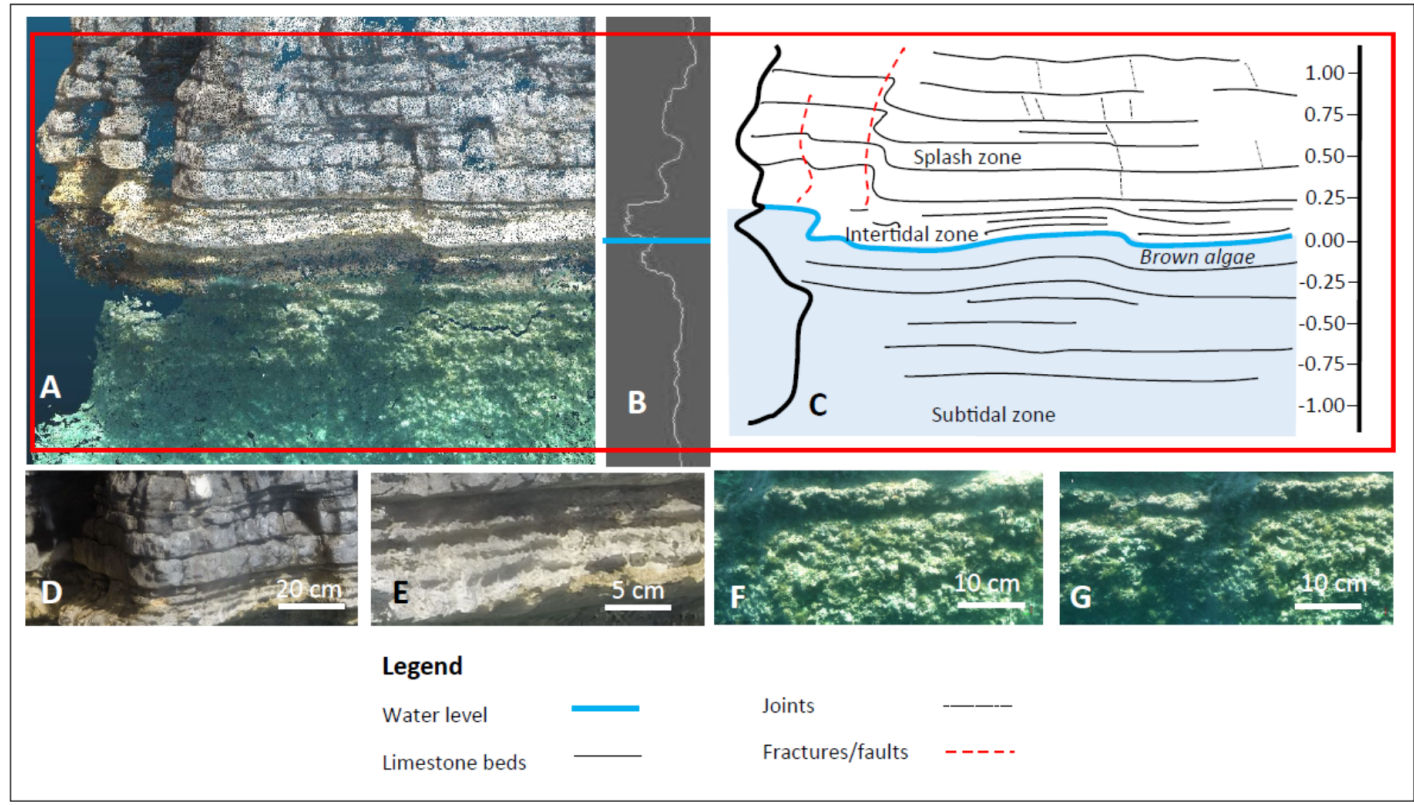

Figure 11. Example of dense cloud of a sector of plunging cliffs at site 2. The dense cloud shows that there are some gaps in the model, but the morphology of the cliff is recognizable. (A) The dense cloud; (B) the profile of the cliff obtained from the dense cloud; (C) geological/geomorphological interpretation of the intertidal and nearshore zone reproduced in (A). The legend is in the bottom center of the figure; $(D, E)$ enlargements of the textured model of the cliff awl; $(\mathbf{F}, \mathbf{G})$ enlargement of the textured model of the cliff bwl. 
The final drawing up of the 3D model of the seawall is shown in Figure 11A,B. A zoom of the textured model, shown in Figure 11C-F, shows the high-resolution and the color range quality Figure 11. shows a sector of the plunging cliffs studied at site 2. The morphology of the cliff is tabular and indented following the horizontal limestone beds. Color belts of biological origin, well described by Schneider [41], show the brownish belt, the white upper intertidal belt, and the grayish supratidal belt. Color belts fit well with the trend of the geological beds, shown in Figure 11A, that range in width from $2 \mathrm{~cm}$ to $15 \mathrm{~cm}$. Awl, the surface of the cliff is bare, with very few organisms (such as gastropods, etc.), while bwl, limestone beds are almost completely covered by organisms. Bwl, the cliff is less indented than awl because organisms cover the limestone beds. Joints, fractures, and rock-mass subdivision are easily recognizable, and together with geological beds, characterize the surface morphology of the cliff. The latter is vertically plunging into the sea, while the tidal notch is lacking, shown in Figure 11B, neither above nor below the sea level. A roughly $10 \mathrm{~cm}$-indentation affects the mean sea level, probably due to the selective abrasion of limestone beds. This confirms the surveys of Furlani et al. [6], as the authors have not found tidal notches in southern Istria. In Figure 11C, a white fresh surface is clearly visible at the top center of the photo and this is due to recent wave abrasion. These white surfaces are common at site 2 and the surroundings [25]. The same considerations go for the remaining part of the studied cliffs.

However, the drone model does not allow the modeling of the submerged part of the coast and the resolution is lower than that obtained with horizontal images, shown in Table 7.

Table 7. Resolution and reprojection errors of the models using awl, bwl, and drone images, as reported by the Metashape processing reports.

\begin{tabular}{cccc}
\hline Source & $\begin{array}{c}\text { Resolution } \\
(\mathbf{m m} / \text { Pixel) }\end{array}$ & $\begin{array}{c}\text { Mean Reprojection Error } \\
\text { (pixel) }\end{array}$ & $\begin{array}{c}\text { Error } \\
(\mathbf{m m})\end{array}$ \\
\hline Time-lapse awl & 1.990 & 1.080 & 2.149 \\
Time-lapse bwl & 0.846 & 1.110 & 0.939 \\
Time-lapse drone & 7.000 & 0.876 & 6.132 \\
\hline
\end{tabular}

In Figure 12, we report the distribution of distances between points of UAV-DP images and horizontal time-lapse images. Errors are commonly lower than $5 \mathrm{~cm}$, and most of them are lower than $2.5 \mathrm{~cm}$.

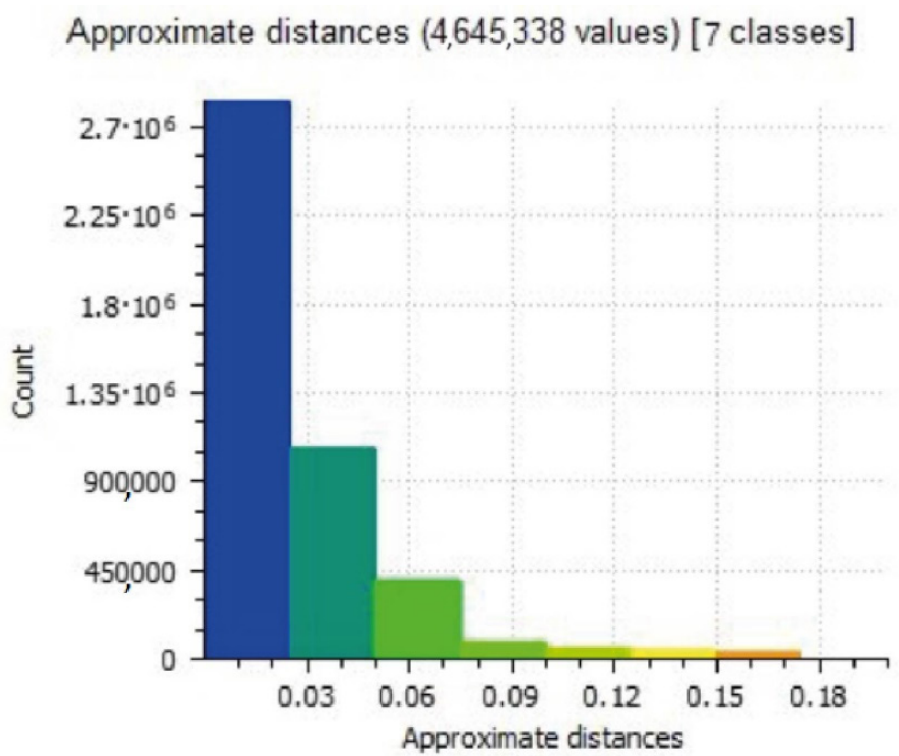

Figure 12. Distribution of distances between points of UAV-DP images and horizontal time-lapse images.

The textured model with drone images is very scenic, but the resolution is lower than the model obtained with horizontal images, in particular close to the water level, shown in Figures 13 and 14. 


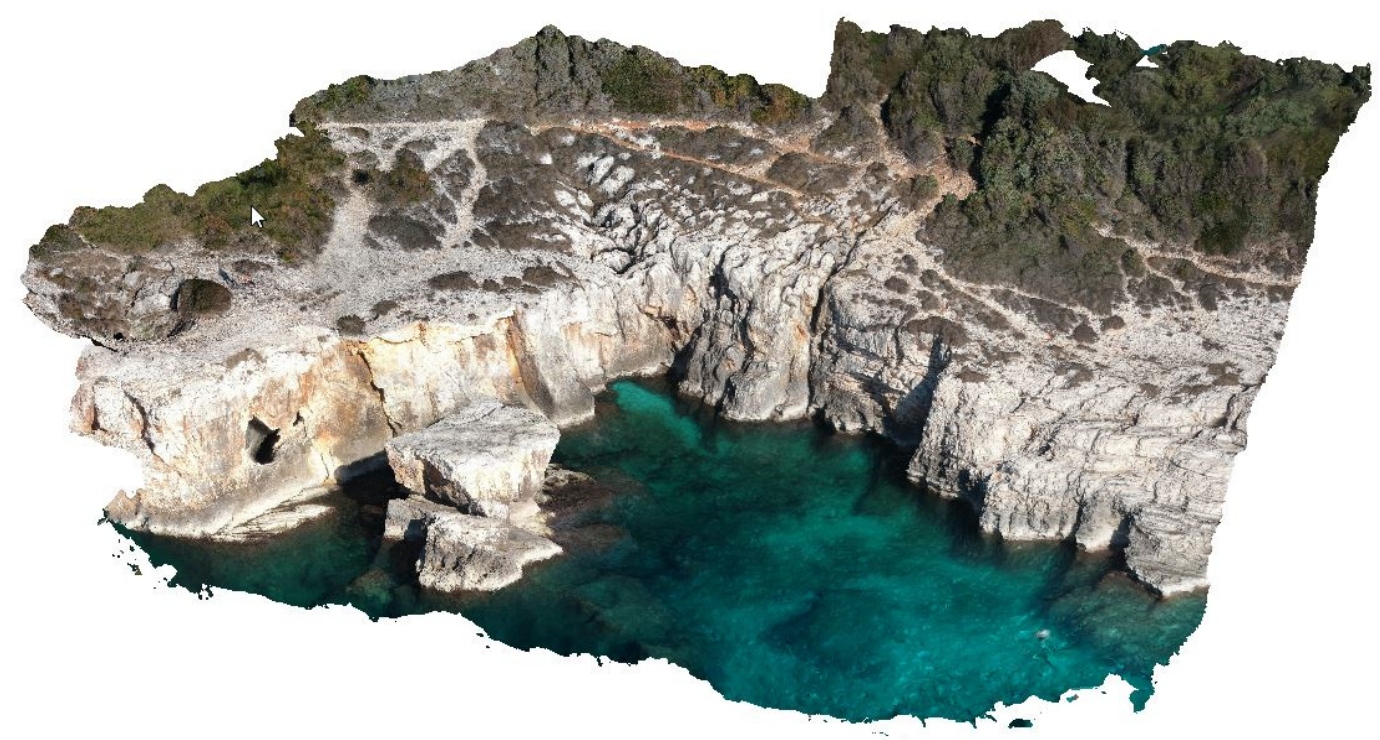

Figure 13. Textured model of site 2 with drone images.

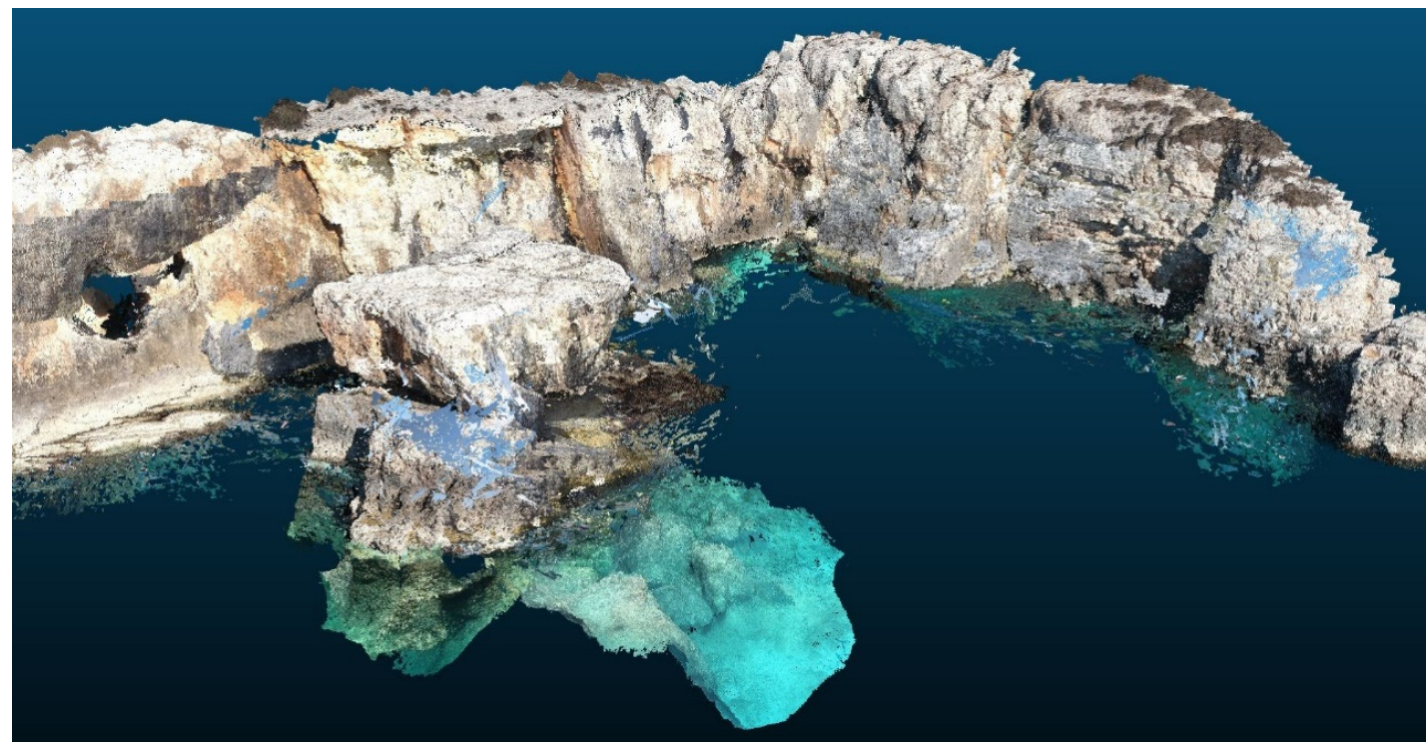

Figure 14. Dense cloud of the emergent and submerged part of the plunging cliffs at Premantura using both horizontal images and tilted drone images.

\section{Discussion}

Rocky coasts, and in particular plunging cliffs, represent a reliable environment to test photogrammetric procedures to build 3D models of intertidal and nearshore zones. Plunging cliffs are particularly suitable to test the alignment of coastal models because cliff walls are often vertical and almost homogeneous from a geomorphological viewpoint both awl and bwl. Moreover, plunging cliffs are particularly interesting for the recurrent presence of sea level markers developing in the intertidal zone, such as marine notches and other specific landforms $[42,43]$ that would be useful to model. Studies on rocky coasts would greatly benefit from 3D reconstructions, in which the submerged and emergent parts of the intertidal zone can be matched in a single model. Moreover, this work illustrates the possibility of using images from the Geoswim archive [5], collected using low-cost equipment with rapid acquisition, to reconstruct the intertidal morphology of long stretches of rocky coastlines. 
The SfM technique has been usually restricted to the independent reconstruction of emergent or underwater objects, respectively through drone/terrestrial photogrammetry or submerged photogrammetric surveys. The resulting 3D representations are very useful for geologists and geomorphologists, as well as archaeologists, as they provide a model to interpret the morphometric parameters of coastal features, such as coastal landforms, geological bedding, etc. [19]. Vertical sea cliffs in submerged environments have also been successfully studied using photogrammetry by combining sideways multibeam echosounder (MBES) and remotely operated vehicle (ROV) videos [44], but intertidal and nearshore zones remain a neglected set. In fact, as aforementioned, the transition zone has rarely been investigated because of inherent differences in the optical settings of the cameras that preclude the common processing of images collected awl and bwl. Recently, [11,14], with very good results, modelled several natural and human-made structures lying or floating at the waterline. Their method can be very useful and reliable for small objects, or short sectors of coast. Moreover, such a task can be accomplished in a relatively short time and with a high degree of precision. The availability of a large number of time-lapse images collected awl and bwl, collected within the Geoswim program [5], directed our efforts at testing the matching of independent models obtained from images collected awl and bwl avoiding the use of metal bars or other targets to perform the matching. This is particularly important in the case of surveys conducted within campaigns along large stretches of coast. In these cases, the time available for the collection of images, field calibration, and target spreading across the study area is very limited. On the contrary, the Geoswim program provides a large number of time-lapse images, which are collected by simply swimming parallel to the coastline. Thus, these images can be used to reproduce the intertidal and nearshore zone and can help provide information for several coastal frameworks.

Photogrammetric models are affected by several types of errors [34], such as the distance of acquisition, and consequently, the variability of the scale of acquisition, camera calibration, image network geometry, surface texture and lighting conditions, ground control point (GCP) characteristics, height of the camera awl and bwl, contrast, light reflection, and photos discarded due to water drops or waves over the dome. Taking all these errors into consideration, we tested the possibility of using these models for rocky coast studies. Figures 10 and 11 show that the alignment fits well, at least when models involve limited sectors of coastline. In this case, the resolution can be up to centimetric. The models obtained in our tests proved to be complete, fast, and quite easy to obtain, and aligned above and below the water interface.

The test performed at site 1 , shows that the resolution of the resulting model is sufficient to measure the size of the sandstone blocks on the wall, to count marine shells, and recognize the species of organisms ranging in size from 1 to $2 \mathrm{~cm}$, shown in Figure 10A,B. The alignment was done through rotating the models by matching prominent landforms recognized on the coast, such as two pipes that are recognizable on the left, shown in Figure 11B. Moreover, the colors relative to different heights of the intertidal zone [43] can easily be distinguished and can be used for ecological studies.

The test performed at site 2 was carried out using both horizontal images collected from the raft and $45^{\circ}$ tilted images collected from the drone, along a $150 \mathrm{~m}$ route, as shown in the jointed model in Figure 13. The model obtained from horizontal time-lapse images, shown in Figure 11 defines a good resolution for geomorphological studies from the centimetric scale up.

The comparison between the resolution of the models, shown in Table 7, shows that the resolution for bwl models is higher $(0.846 \mathrm{~mm} / \mathrm{pixel})$ than awl models $(1.990 \mathrm{~mm} / \mathrm{pixel})$, but the resolution of the drone model is significantly lower $(7.000 \mathrm{~mm} / \mathrm{pixel})$, because images were collected further away from the cliff. Bwl models can be significantly affected by turbidity, which reduces the resolution and significantly changes the colors of the texturized model, as shown in Figure 10. Moreover, as the morphological complexity of the cliff increases, the models can produce data gaps, shown in Figure 11A, which can reduce the reproduced rock surface. However, this problem affects both drone and horizontal time-lapse acquisitions. For this reason, it is fundamental to collect images with very good sea and weather conditions. The visual comparison of the models, shown in Figure 14, 
has shown that, using the same camera resolution, awl models are more detailed than drone models, because of the higher distance of the drone camera from the intertidal zone.

The swimming survey was carried out a few meters from the cliff, while the UAV surveys were significantly further away. In particular, images collected from the swim surveys are more detailed on vertical surfaces, because of an inherent difficulty in collecting images with drones from vertical surfaces. Conversely, UAV-DP acquisition is very reliable in modelling horizontal, or slightly inclined rock surfaces, shown in Figure 15A. For example, swim survey images cannot model the top of the stack, shown in Figure 15B, but the model must be integrated with UAV-DP images. What is more, underwater, common commercial drone modelling is completely unreliable, while horizontal images permit the collection of images, even if with a reduced resolution due to the lower visibility bwl. The differences in light conditions of the two models are due to the software analysis of images collected during two surveying days. However, this fact does not affect the resolution of the 3D models.

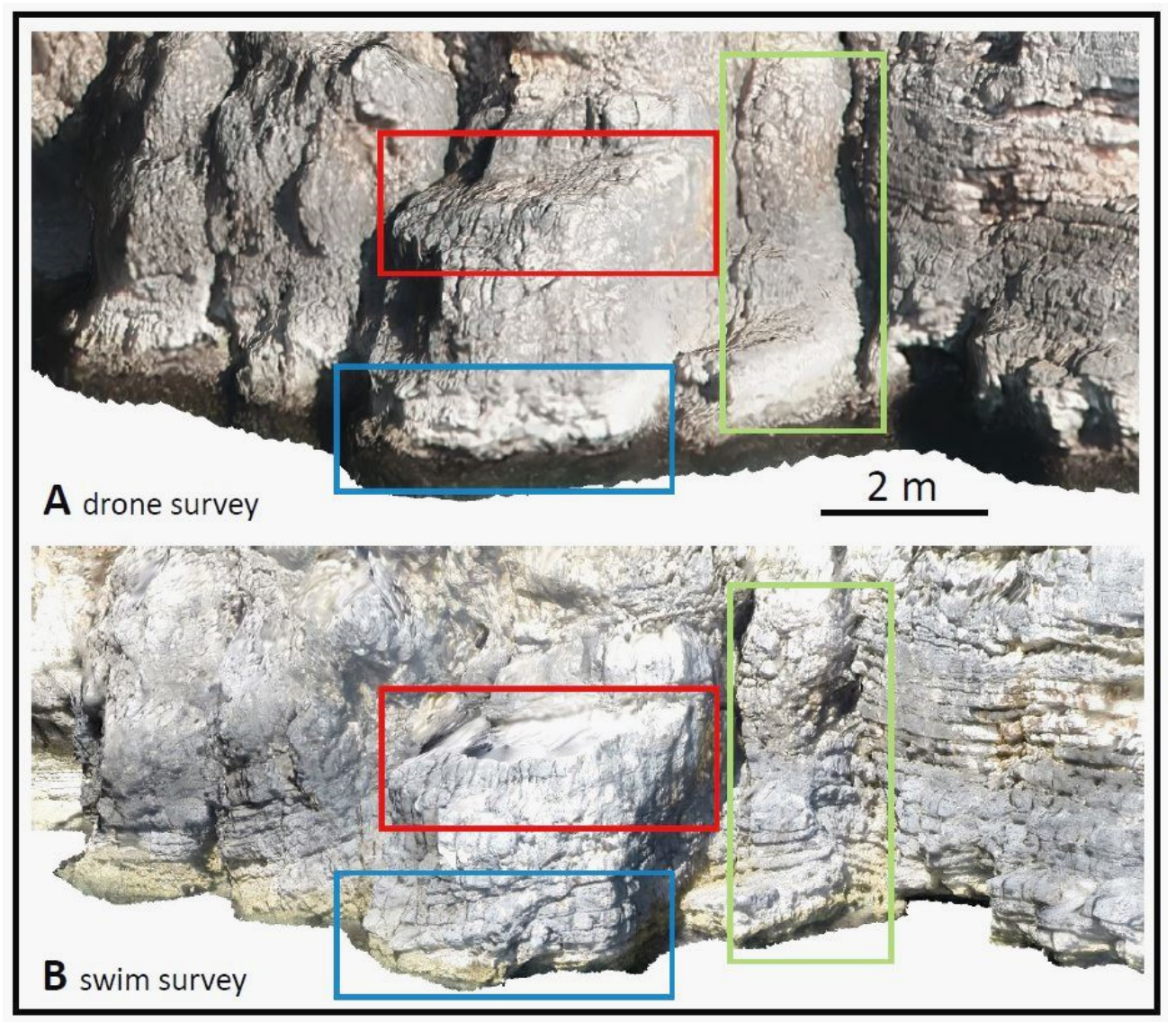

Figure 15. Comparison between a mesh model obtained using a drone survey (A) and a swim survey (B). The resolution of the sub-horizontal surfaces is higher with the drone survey, while the resolution of vertical rock surfaces in the upper tidal and nearshore zone is higher with swim survey.

To summarize the pros and cons of the discussed approach, we present a SWOT matrix, shown in Table 8. Swim surveys are particularly effective when modelling plunging cliffs, in particular the intertidal and nearshore zone, when awl and bwl the general morphology is homogeneous, shown in Table 8. 
Table 8. The SWOT matrix. This analysis of the strengths allows for the definition of the characteristics of the method that give an advantage over other approaches of coastal modelling; the weaknesses allow for the definition of the characteristics of the approach that need improvements; the opportunities define the goals, or the elements that the project could exploit to its advantage, while the threats analyze the overall obstacles to using the method.

\begin{tabular}{|c|c|c|}
\hline SWOT Analysis & INTERNAL & EXTERNAL \\
\hline HELPFUL & $\begin{array}{l}\text { Strengths: } \\
\text { - The method represents a useful way to model rocky coast topography } \\
\text { in microtidal environments, using low-cost instruments; } \\
\text { - The acquisition and elaboration times are relatively short; } \\
\text { - The 3D models can be improved with subsequent surveys in different time } \\
\text { periods, or by using a drone; } \\
\text { - The method permits the study of wide sections of coastline; } \\
\text { - Modelization processes need to build independent underwater } \\
\text { and submerged photogrammetry. }\end{array}$ & $\begin{array}{l}\text { Opportunities: } \\
\text { Data collected can implement a database of rocky coast images; } \\
\text { The models are created in scale and can be manipulated later; } \\
\text { The models can be compared to each other over time; } \\
\text { A wide range of applications in the field of marine environments, such as } \\
\text { coastal erosion processes, biological and ecological conservation, } \\
\text { and the survey of human-made intertidal structures, such as artificial quays } \\
\text { and port structures, are suited to this approach. }\end{array}$ \\
\hline HARMFUL & $\begin{array}{l}\text { Weakness: } \\
\text { - Images collected in shaded environments, can be strongly affected by a lack } \\
\text { of light; } \\
\text { - Images are strongly affected by the sun's lighting; } \\
\text { The alignment process could require several steps of pre-process elaboration, } \\
\text { such as color correction, etc.; } \\
\text { Many kilometers of rocky coast are surveyed through rapid campaigns, so } \\
\text { image acquisition must be optimized in relation to other data; } \\
\text { Low-lying rock coasts are difficult to survey using this approach, because } \\
\text { cameras are set horizontally. In this case, UAV-DP outputs might be necessary } \\
\text { to add complementary information. }\end{array}$ & $\begin{array}{l}\text { Threats: } \\
\text { - Data collected during bad sea conditions may prove unreliable for the SfM } \\
\text { method, in particular, in the intertidal rather than in the nearshore zone; } \\
\text { Raft roll due to waves can produce blurry and incomplete images; } \\
\text { - Images collected bwl can be affected by turbidity, which can reduce or prevent } \\
\text { modelling processes; } \\
\text { The pattern of coastal landforms, and details of such structures, might be } \\
\text { recognizable only at a certain distance from the coast, which should be } \\
\text { maintained during the entire survey. }\end{array}$ \\
\hline
\end{tabular}


Conversely, the acquisition of horizontal images on low-lying rocky coasts or shore platforms is completely impossible, in particular in the submerged sections [5]. Unfortunately, the collection of images in the latter segment of sea cliffs can be strongly influenced by sea conditions. High turbidity can significantly reduce the number of reliable images, because it reduces the resolution of underwater photos creating shaded images with low visibility. At its worst, with very rough seas, turbidity can completely prevent the building of 3D models. Low light levels also affect the quality of images, because part of the coastline may be lacking image coverage, therefore, high values of local ruggedness decrease the feasibility of building effective models. Furthermore, the sectors of the coast without direct light are all but impossible to model using SfM, because the software cannot align the models. The same goes for backlit images. Local topographic obstacles along the swimming direction may force the operator to instantly change the image direction of acquisition, in order to achieve the best coverage of the coastline under study, but the final resolution of the model will be reduced. Alongside problems concerning image quality, even a lack of GPS signal may reduce the accuracy of the model, in particular within sea caves.

$3 \mathrm{D}$ models of the intertidal and nearshore zone are expected to have a wide range of applications in the fields of Earth Sciences, such as geomorphology, geology, biology, ecology, as well as surveys of harbors and other human-made structures.

\section{Conclusions}

The approach discussed here suggests that the intertidal and nearshore zones can be successfully described by 3D models obtained using time-lapse images, following precise procedures and under good weather and sea conditions. The merged models allow for the analysis of morphological, but also morphometric features of the intertidal and nearshore zone, where several coastal landforms, including intertidal notches, biogenic or coastal karst holes, furrows and channels, joints, faults, potholes, blocks or boulders of marine or subaerial origin, stacks and sea caves, etc., occur.

Independent models of the emergent and submerged part can be generated using common SfM software and then merged using prominent landforms located on sea cliffs along the surveyed route.

The tests highlighted that the generation of 3D models of the intertidal zone are strongly conditioned by several parameters, such as light transmission in and between air and water, weather and sea conditions, the rapid changes in the water level due to waves, as well as by water turbidity, which may reduce or even prevent 3D modelling. To improve the accuracy of the models, further photographic campaigns in different tidal heights, such as high and low water, can be performed in order to supplement data at the waterline. The comparison with UAV-DP outputs showed that drones permit the mapping of large stretches of coastline and are very reliable for horizontal and sub-horizontal rock surfaces, but the resolution and detail of 3D models collected from swim surveys are higher in the intertidal and nearshore zone. In situations of an abundance of flat surfaces near the water level, it is necessary to integrate the models with UAV-DP outputs.

Author Contributions: Swimming operations, S.F., V.V. and V.M.; drone surveys, S.D.; original idea, S.F. and V.M.; conceptualization, all authors; writing — original draft, S.F. and V.V.; supervision, S.F.; writing—review and editing, S.F. and V.V. All authors have read and agreed to the published version of the manuscript.

Funding: Funding for this study was provided by the University of Trieste for field activities and instruments. The Falck family partially funded its publication.

Acknowledgments: Special thanks to the Geoswim program (Resp. Stefano Furlani, University of Trieste) and FRA project ELAB (Erosion Laboratory, University of Trieste). A special thanks to Falck family.

Conflicts of Interest: The authors declare no conflict of interests. 


\section{Abbreviations}

The following abbreviations are used in the manuscript:

$\begin{array}{ll}\text { UAVs } & \text { Unmanned Aerial Vehicles } \\ \text { SfM } & \text { Structure-from-Motion } \\ \text { awl } & \text { above water level } \\ \text { blw } & \text { below water level } \\ \text { LiDAR } & \text { Light Detection and Ranging } \\ \text { FOV } & \text { Field of View } \\ \text { GDS } & \text { Ground Sampling Distance } \\ \text { TPs } & \text { Tie Points } \\ \text { ODs } & \text { Orientation Devices } \\ \text { DP } & \text { Digital Photography } \\ \text { MBES } & \text { Multibeam Echosounder } \\ \text { ROV } & \text { Remotely Operated Vehicle } \\ \text { GCP } & \text { Ground Control Point }\end{array}$

\section{References}

1. Kennedy, D.M.; Stephenson, W.J.; Naylor, L.A. Introduction to the rock coasts of the world. Geol. Soc. Lond. Mem. 2014, 40, 1-5. [CrossRef]

2. Lewis, J.R. The Littoral Zone on Rocky Shores: A Biological or Physical Entity? Oikos 1961, 12, $280-301$. [CrossRef]

3. Biolchi, S.; Furlani, S.; Devoto, S.; Gauci, R.; Castaldini, D.; Soldati, M. Geomorphological identification, classification and spatial distribution of coastal landforms of Malta (Mediterranean Sea). J. Maps 2016, 12, 87-99. [CrossRef]

4. Biolchi, S.; Furlani, S.; Covelli, S.; Busetti, M.; Cucchi, F. Morphoneotectonic map of the coastal sector of the Gulf of Trieste (NE Italy). J. Maps 2016, 12, 936-946. [CrossRef]

5. Furlani, S. Integrated observational targets and instrumental data on rock coasts through snorkel surveys. Mar. Geol. 2020. [CrossRef]

6. Furlani, S.; Ninfo, A.; Zavagno, E.; Paganini, P.; Zini, L.; Biolchi, S.; Antonioli, F.; Coren, F.; Cucchi, F. Submerged notches in Istria and the Gulf of Trieste: Results from the Geoswim Project. Quat. Int. 2014, 332, 37-47. [CrossRef]

7. Furlani, S.; Antonioli, F.; Cavallaro, D.; Chirco, P.; Caldareri, F.; Martin, F.F.; Morticelli, M.G.; Monaco, C.; Sulli, A.; Quarta, G.; et al. Intertidal notches, coastal landforms and relative sea-level changes during the Late Quaternary at Ustica Island (Tyrrhenian Sea, Italy). Geomorphology 2017, 299, 94-106. [CrossRef]

8. Furlani, S.; Antonioli, F.; Gambin, T.; Gauci, R.; Ninfo, A.; Zavagno, E.; Micallef, A.; Cucchi, F. Marine notches on the Maltese Islands (Central Mediterranean Sea). Quat. Int. 2017, 439, 158-168. [CrossRef]

9. Furlani, S.; Piacentini, D.; Troiani, F.; Biolchi, S.; Rocchegiani, M.; Tamburini, A.; Vaccher, V.; Antonioli, F.; Devoto, S.; Nesci, O.; et al. Tn (tidal notches) at the Conero area (W Adriatic coast): Implications for coastal instability. Geogr. Fis. e Din. Quat. 2018, 41,33-46.

10. Westoby, M.J.; Brasington, J.; Glasser, N.F.; Hambrey, M.J.; Reynolds, J.M. 'Structure-from-Motion'photogrammetry: A low-cost, effective tool for geoscience applications. Geomorphology 2012, 179, 300-314. [CrossRef]

11. Menna, F.; Nocerino, E.; Troisi, S.; Remondino, F. Joint alignment of underwater and above-the-water photogrammetric $3 \mathrm{~d}$ models by independent models adjustment. Int. Arch. Photogramm. Remote Sens. Spat. Inf. Sci. 2015, XL-5-W5, 143-151. [CrossRef]

12. Carrivick, J.L.; Smith, M.W.; Quincey, D.J. Structure from Motion in the Geosciences; John Wiley \& Sons: New York, NY, USA, 2016.

13. Ružić, I.; Marović, I.; Benac, Č.; Ilić, S. Coastal cliff geometry derived from structure-from-motion photogrammetry at Stara Baška, Krk Island, Croatia. Geo Mar. Lett. 2014, 34, 555-565. [CrossRef]

14. Nocerino, E.; Menna, F.; Farella, E.; Remondino, F. 3D virtualization of an underground semi-submerged cave system. Int. Arch. Photogramm. Remote Sens. Spat. Inf. Sci. 2019, 42, 857-864. [CrossRef] 
15. Remondino, F.; El-Hakim, S. Image-based 3D modelling: A review. Photogramm. Rec. 2006, 21, $269-291$. [CrossRef]

16. Matthews, N.A. Aerial and Close-Range Photogrammetric Technology: Providing Resource Documentation, Interpretation, and Preservation; US Department of the Interior, Bureau of Land Management, National Operations Center: Denver, CO, USA, 2008.

17. Fraser, C.S.; Cronk, S. A hybrid measurement approach for close-range photogrammetry. ISPRS J. Photogram Remote Sens. 2009, 64, 328-333. [CrossRef]

18. Abadie, A.; Boissery, P.; Viala, C. Georeferenced underwater photogrammetry to map marine habitats and submerged artificial structures. Photogramm. Rec. 2018, 33, 448-469. [CrossRef]

19. Drap, P.; Merad, D.; Hijazi, B.; Gaoua, L.; Nawaf, M.; Saccone, M.; Chemisky, B.; Seinturier, J.; Sourisseau, J.C.; Gambin, T.; et al. Underwater photogrammetry and object modeling: A case study of Xlendi Wreck in Malta. Sensors 2015, 15, 30351-30384. [CrossRef]

20. Micheletti, N.; Chandler, J.H.; Lane, S.N. Structure from motion (SFM) photogrammetry. Br. Soc. Geomorphol. Geomorphol. Tech. 2015, 2, 1-12.

21. Teague, J.; Scott, T. Underwater photogrammetry and 3D reconstruction of submerged objects in shallow environments by ROV and underwater GPS. J. Mar. Sci. Technol. Japan 2017, 1, 1-5.

22. Remondino, F.; Barazzetti, L.; Nex, F.; Scaioni, M.; Sarazzi, D. UAV photogrammetry for mapping and 3d modelling-current status and future perspectives. Int. Arch. Photogramm. Remote Sens. Spat. Inf. Sci. 2011, 38, 25-31.

23. Drap, P.; Merad, D.; Boi, J.-M.; Mahiddine, A.; Peloso, D.; Chemisky, B.; Seguin, E.; Alcala, F.; Bianchimani, O. Underwater multimodal survey: Merging optical and acoustic data. In Underwater Sascapes; Musard, O., Le Du-Blayo, L., Francour, P., Beurier, J.P., Feunteun, E., Talassinos, L., Eds.; Springer: Cham, Switzerland, 2014; pp. 221-238.

24. Vlahović, I.; Tišljar, J.; Velić, I.; Matičec, D. Evolution of the adriatic carbonate platform: Palaeogeography, main events and depositional dynamics. Palaeogeogr. Palaeoclimatol. Palaeoecol. 2005, 220, 333-360. [CrossRef]

25. Biolchi, S.; Demaniel, C.; Devoto, S.; Korbar, T.; Macovaz, V.; Sciccchitano, G.; Vilibic, I.; Furlani, S. Impact of the October 2018 Storm Vaia on Coastal Boulders in the Northern Adriatic Sea. Water 2019, 11, 2229. [CrossRef]

26. Carrera, F.; Cerasuolo, M.; Tomasin, A.; Canestrelli, P. La nebbia a Venezia nel quarantennio 1951-1990. Analisi comparata degli andamenti di visibilità, pressione, temperatura e vento. Istituto Veneto di Scienze, Lettere ed Arti, Commissione di studio dei provvedimenti per la conservazione e difesa della laguna e della città di Venezia. Rapporti e Studi 1995, 12, 235-271.

27. Dorigo, L. Ufficio idrografico. La laguna di Grado e le sue foci: Ricerche e rilievi idrografici. Magistrato alle Acque 1965, 155, 231.

28. Polli, S. Tabelle di Previsione delle Maree per Trieste e L'Adriatico Settentrionale per L'anno 1971; Istituto Sperimentale Talassografico "Francesco Vercelli": Trieste, Italy, 1970.

29. Dal Cin, R.; Simeoni, U. A model for determining the classification, vulnerability and risk in the southern coastal zone of the Marche (Italy). J. Coast Res. 1994, 8, 18-29.

30. Cavaleri, L.; Bergamasco, L.; Bertotti, L.; Bianco, L.; Drago, M.; Iovenitti, L.; Lavagnini, A.; Liberatore, G.; Martorelli, S.; Mattioli, F.; et al. Wind and waves in the northern Adriatic Sea. Il Nuovo Cimento C 1996, 19, 1-36. [CrossRef]

31. Raicich, F.; Colucci, R.R. A near-surface temperature time series from Trieste, northern Adriatic Sea (1899-2015). Earth Syst. Sci. Data 2019, 11, 761-768. [CrossRef]

32. Menna, F.; Nocerino, E.; Fassi, F.; Remondino, F. Geometric and optic characterization of a hemispherical dome port for underwater photogrammetry. Sensors 2016, 16, 48. [CrossRef]

33. Mosbrucker, A.R.; Major, J.J.; Spicer, K.R.; Pitlick, J. Camera system considerations for geomorphic applications of SfM photogrammetry. Earth Surf. Process. Landf. 2017, 42, 969-986. [CrossRef]

34. Eltner, A.; Kaiser, A.M.; Castillo, C.; Rock, G.; Neugirg, F.; Abellán, A. Image-based surface reconstruction in geomorphometry-merits, limits and developments. Earth Surf. Dyn. 2016, 4, 359-389. [CrossRef]

35. Agisoft. Agisoft Metashape User Manual, Professional Edition, Version 1.5; Agisoft: St. Petersburg, Russia, 2019.

36. Brooke-Holland, L. Unmanned Aerial Vehicles (Drones): An Introduction; House of Commons Library: London, UK, 2012. 
37. Giordan, D.; Hayakawa, Y.; Nex, F.; Remondino, F.; Tarolli, P. Review article: The use of remotely piloted aircraft systems (RPASSs) for natural hazards monitoring and management. Nat-Hazards Earth Syst. Sci. 2018, 18, 1079-1096. [CrossRef]

38. Yao, H.; Qin, R.; Chen, X. Unmanned Aerial Vehicle for Remote Sensing Applications-A Review. Remote Sens. 2019, 11, 1443. [CrossRef]

39. Cirilli, S. Marea Astronomica 2019; Technical Report; Ente Tutela Patrimonio Ittico, Regione Friuli Venezia Giulia: Udine, Italy, 2019; p. 16.

40. Cirilli, S. Marea Astronomica 2020; Technical Report; Ente Tutela Patrimonio Ittico, Regione Friuli Venezia Giulia: Udine, Italy, 2020; p. 16.

41. Schneider, J. Biological and inorganic factors in the destruction of limestone coasts. Contrib. Sedimentol. 1976, 6, 1-112.

42. Antonioli, F.; Lo Presti, V.; Anzidei, M.; Deiana, G.; De Sabata, E.; Ferranti, L.; Furlani, S.; Mastronuzzi, G.; Orrù, P.; Pagliarulo, R.; et al. Tidal notches in the Mediterranean Sea. Quat. Sci. Rev. 2015, 119, 1-19. [CrossRef]

43. Trenhaile, A.S. Coastal notches: Their morphology, formation, and function. Earth Sci. Rev. 2015, 150, 285-304. [CrossRef]

44. Robert, K.; Huvenne, V.A.; Georgiopoulou, A.; Jones, D.O.; Marsh, L.; Carter, G.D.; Chaumillon, L. New approaches to high-resolution mapping of marine vertical structures. Sci. Rep. 2017, 7, 9005. [CrossRef]

(C) 2020 by the authors. Licensee MDPI, Basel, Switzerland. This article is an open access article distributed under the terms and conditions of the Creative Commons Attribution (CC BY) license (http://creativecommons.org/licenses/by/4.0/). 